\title{
ANALISIS KOREKSI FISKAL DALAM RANGKA PERHITUNGAN PPH BADAN PADA PT. BANK PERKREDITAN RAKYAT NUSA UTARA
}

\author{
Brilliant Joy Leonardo Kalangie ${ }^{1}$ \\ Grace B. Nangoi ${ }^{2}$ \\ Inggriani Elim $^{3}$ \\ Fakultas Ekonomi dan Bisnis, Jurusan Akuntansi \\ Universitas Sam Ratulangi Manado \\ email: leonardo.kalangieBK@gmail.com
}

\begin{abstract}
ABSTRACK
The income statement is something that is very important in the financial statements. In the income statement presents income (revenue), costs (expenses) and income (profit / losses) a company within a certain time period or periods. Income statement itself is also a financial statement must be derived from the accounting system, both made in accordance with provisions in the Law - Tax Law as well as those in charge based financial Accounting Standards (GAAP). Basically, both of these things (Law - Tax Law and the Financial Accounting Standards) regulate the same thing that is about how much the amount of the charge to the consumer. However, the fiscal correction, we can find something different. This difference is what happens when the accounting of income in measuring too low and unnatural because of special treatment that favor the occurrence of this. Fiscal correction itself is a correction or adjustment must be done before calculating the taxpayer's income tax for corporate taxpayers and tax personal use of accounting in calculating taxable income.

The aim of this study was to determine the fiscal correction is done by PT. Rural Bank Nusa North in order calculating corporate income tax. This study took place at the office of PT. Rural Bank Nusa North. The company is located at Jl. Nusantara No. 98 Complex Bersehati Market Manado. The object of this study is the income / loss of PT. Rural Bank Nusa North.

This study uses descriptive qualitative research because in practice, such as data, analysis and interpretation of the meaning and the data obtained. In this study, the author will study the financial statements of the profit-rui in 2013 and 3014 were obtained from the company. Then analyzed whether fiscal reconciliation process made are correct and in accordance with regulations Regulations - Tax regulations prevailing in Indonesia at this time.

The results showed that the company has made a statement profit / loss of commercial accordance with the applicable accounting standards, and has made statements of income / tax loss properly in accordance with the tax laws and regulations. So it can be taxable income of PT. RB Nusa North, then calculate the income tax in accordance with the calculation of the applicable tax rate on taxable income (PKP) from PT. RB Nusa North.
\end{abstract}

\section{Keywords: Fiscal Correction, Reconciliation Fiscal, Income Statement}

\section{PENDAHULUAN}

\section{Latar Belakang}

Laporan laba-rugi merupakan sesuatu hal yang amat penting dalam laporan keuangan. Laporan labarugi ini sendiri juga merupakan suatu laporan keuangan yang harus dihasilkan dari system akuntansi, baik dibuat berdasarkan dengan ketentuan yang dalam Undang - Undang Perpajakan maupun yang ditetapkan berdasarkan Standar Akuntansi keuangan (SAK). Secara mendasar, kedua hal ini (Undang - Undang Perpajakan dan Standar Akuntansi Keuangan) mengatur suatu hal yang sama yakni tentang seberapa besar jumlah yang dibebankan kepada konsumen. Namun dalam koreksi fiskal, kita dapat menemukan suatu hal yang berbeda. Perbedaan ini terjadi apabila dari sisi akuntansi penghasilan diukur terlalu rendah dan tidak wajar dikarenakan adanya perlakuan khusus yang mendukung terjadinya hal ini. Koreksi fiskal itu sendiri merupakan suatu koreksi atau 
penyesuaian yang harus dilakukan wajib pajak sebelum menghitung Pajak Penghasilan bagi wajib pajak badan dan wajip pajak pribadi yang menggunakan pembukuan dalam penghitungan peng hasilan kena pajak.

Tidak terlepas dari fenomena-fenomena yang terjadi dalam penyesuaian laporan keuangan dari perusahaanperusahaan, perkembangan sektor perbankan juga patut untuk dicermati. Sektor ini merupakan salah satu sektor yang masih bertahan di tengah berbagai kondisi perekonomian di Indonesia.

Bank merupakan suatu badan usaha yang menghimpun dana dari masyarakat dalam bentuk simpanan, dan menyalurkan kembali kepada masyarakat dalam bentuk kredit atau bentuk lainnya dalam rangka meningkatkan tarif hidup masyarakat. Pada dasarnya bank harus menciptakan kuatitas produktif yang baik agar dapat meningkatkan pendapatan dan dengan demikian laba usaha akan menjadi semakin besar. Laba usaha inilah yang akan menjadi komponen dalam memperbesar modal usaha

PT. Bank Perkreditan Rakyat Nusa Utara adalah perusahaan yang bergerak di bidang perbankan untuk membantu pertumbuhan ekonomi daerah agar lebih berkembang untuk kemajuan bersama. BPR memberikan produk-produk dalam bentuk kredit maupun tabungan deposito. Atas dasar inilah penulis ingin mengamati bagaimana perusahaan ini menyikapi perbedaan-perbedaan yang terjadi antara laba rugi komersial dan laba rugi fiskal berdasarkan Standar Akuntansi Keuangan dan serta Undang-Undang perpajakan yang berlaku dengan mengangkat topik "Analisis Koreksi Fiskal dalam rangka perhitungan PPh badan pada PT. Bank Perkreditan Rakyat Nusa Utara".

\section{Rumusan Masalah}

Berdasarkan latar belakang di atas, maka dapat ditarik rumusan masalah apakah koreksi fiskal dalam rangka perhitungan Pajak Penghasilan Badan pada PT. Bank Perkreditan Rakyat Nusa Utara sudah sesuai dengan peraturan Perpajakan yang berlaku?

\section{Tujuan Penelitian}

Tujuan dari penelitian ini adalah untuk mengetahui koreksi fiskal yang dilakukan oleh PT. Bank Perkreditan Rakyat Nusa Utara dalam rangka perhitungan PPh badan.

\section{Akuntansi Pajak}

\section{TINJAUAN PUSTAKA}

Akuntansi pajak adalah akuntansi yang diterapkan dengan tujuan untuk menetapkan besarnya pajak terhutang. Fungsi akuntansi pajak ini adalah untuk mengolah data kuantitatif yang akan digunakan untuk menyajikan laporan keuangan yang memuat perhitungan pepajakan.

\section{Pengertian Pajak}

Pajak adalah iuran wajib rakyat kepada Negara berdasarkan Undang - Undang sehingga dapat di paksakan dengan tidak mendapat balas jasa secara langsung. Bagi perusahaan pajak merupakan sebuah tanggung jawab dan kewajiban yang harus dibayarkan kepada Negara, atas kegiatan yang dilakukan di dalam suatu Negara.

Menurut Sumitro (2011 : 1) “ Pajak adalah iuran rakyat pada kas Negara berdasarkan Undang Undang (kontrak prestasi) yang langsung dapat di tunjukan dan yang digunakan untuk membayar pengeluaran umum". "Dapat dipaksakan" mempunyai arti, apabila utang pajak tidak di bayar, utang tersebut ditagih dengan kekerasan, seperti surat paksa, sita, lelang dan sandera. Dengan demikian, ciri-ciri yang melekat pada pengertian pajak adalah sebagai beriku.

1. Pajak dipungut berdasarkan Undang - Undang

2. Jasa timbal tidak ditunjukan secara langsung.

3. Pajak dipungut oleh pemeritah, baik pemerintah pusat maupun pemerintah daerah.

4. Dapat dipaksakan (bersifat yuridis)

\section{Pajak Penghasilan}

Pajak penghasilan pertama kali diatur dalam Undang-undang nomor 7 tahun 1983 tentang pajak penghasilan, lalu direvisi pada Undang-undang nomor 7 tahun 1991, diperbaharui pada tahun 1994 pada Undang-undang nomor 10 serta nomor 17 tahun 2000 dan perubahan terbaru dengan Undang-undang nomor 36 tahun 2008.

Bedasarkan ketentuan Undang-undang perpajakan nomor 36 tahun 2008 pasal 6 ayat 1 menyatakan bahwa "besarnya penghasilan kena pajak bagi wajib pajak dalam negeri dan bentuk usaha tetap, ditentukan 
berdasarkan penghasilan bruto dikurangi biaya untuk mendapatkan, menagih, dan memelihara penghasilan". Hal ini dimaksudkan jelas agar supaya setiap pajak penghasilan akan selalu tepat dan tak akan terjadi kekeliruan dalam pemungutannya.

Menurut Prabowo (2008:34) pajak penghasilan adalah suatu pungutan resmi yang ditujuakan kepada masyarakat yang berpenghasilan yang diterima dan diperoleh dalam tahun pajak, untuk kepentingan Negara dan masyarakat dalam hidup berbangsa dan bernegara sebagai suatu kewajiban yang harus dilaksanakan.

\section{Pengertian Koreksi Fiskal}

Koreksi fiskal adalah koreksi atau penyesuaian yang harus dilakukan oleh wajib pajak sebelum menghitung Pajak Penghasilan (PPh) bagi wajib pajak badan dan wajib pajak orang pribadi. Koreksi fiskal terjadi karena adanya perbedaan perlakuan penghasilan maupun biaya antara akuntansi komersial dengan akuntansi fiskal/pajak. Akibat koreksi fiskal dari Laporan Keuangan komersial menjadi Laporan Keuangan fiskal menyebabkan perbedaan antara laba komersial dengan laba fiskal.

Koreksi fiskal dilakukan apabila terdapat perbedaan antara standar, metode atau praktek akuntansi yang digunakan dalam penyusunan laporan keuangan komersil dengan laporan keuangan fiskal (menurut ketentuan perpajakan). Terjadinya perbedaan-perbedaan antara Standar Akuntansi Keuangan disebabkan oleh adanya berbagai kepentingan dari negara dalam memanfaatkan pajak sebagai salah satu komponen kebijakan fiskal.

Menurut Gustian Djuanda (2006:15), beberapa perbedaan antara Laporan Keuangan Komersial dan Laporan Keuangan Fiskal yang menyebabkan koreksi fiskal dalah sebagai berikut:

1. Perbedaan konsep pendapatan

2. Perbedaan cara pengukuran pendapatan

3. Perbedaan pengakuan pendapatan

4. Perbedaan konsep biaya

5. Perbedaan cara pengukuran dan pengakuan biaya

Perbedaan-perbedaan yang dikemukakan di atas, dalam koreksi laporan keuangan komersil (akuntansi) dan laporan keuangan fiskal, dikelompokkan lagi ke dalam dua golongan yaitu yang dikenal sebagai perbedaan sementara (temporary difference) dan perbedaan tetap (permanent difference). Adapun penjelasan atas kedua perbedaan tersebut adalah sebagai berikut:

1. Beda Tetap, yaitu penghasilan yang diakui dalam perhitngan laba neto untuk akuntansi komersial tetapi tidak diakui dalam perhitungan akuntansi pajak.

Contoh penghasilan : sumbangan, penghasilan bunga deposito

Contoh biaya : biaya sumbangan, biaya sanksi perpajakan.

2. Beda Waktu, yaitu penghasilan dan biaya yang dapat diakui saat ini oleh akuntansi komersial, tetapi tidak dapat diakui sekaligus oleh akuntansi pajak, biasanya karena perbedaan metode pengakuan.

Contoh penghasilan : pendapatan laba selisih kurs.

Contoh biaya : : biaya penyusutan, biaya sewa

\section{Jenis Koreksi Fiskal}

Terdapat dua jenis koreksi fiskal yaitu koreksi fiskal positif dan koreksi fiskal negatif. Koreksi fiskal positif adalah koreksi / penyesuaian yang akan mengakibatkan meningkatnya laba kena pajak yang pada akhirnya akan membuat PPh Badan Terhutangnya juga akan meningkat. Sedangkan koreksi fiskal negative adalah koreksi atau penyesuaian yang akan mengakibatkan menurunnya laba kena pajak yang akan membuat PPh badan terhutangnya juga akan menurun.

\section{METODE PENELITIAN}

\section{Jenis Penelitian}

Penelitian ini menggunakan metode penelitian deskriptif kualitatif karena dalam pelaksanaannya meliputi data, analisis dan interpretasi tentang arti dan data yang diperoleh. Metode deskriptif adalah suatu meotde dalam meneliti status kelompok manusia, suatu objek, suatu set kondisi, suatu sistem pemikiran, ataupun suatu kelas peristiwa pada masa sekarang (Nazir, 2005 : 54). Sedangkan metode penelitian kualitatif adalah penelitian yang berlandaskan pada filsafat postpositifme, digunakan untuk meneliti pada kondisi objek yang alamiah dimana peneliti adalah sebagai instrumen kunci, pengambilan sample sumber dan data dilakukan secara purposive, teknik pengumpulan data dilakukan dengan triangulasi (gabungan) analisis data bersifat 
induktif/kualitatif, dan hasil penelitian kualitatif lebih menekankan pada makna generalisasi (Sugiono, 2009 : $15)$.

\section{Tempat Penelitian}

Penelitian ini bertempat pada kantor PT. Bank Perkreditan Rakyat Nusa Utara. Perusahaan ini terletak di Jl. Nusantara No. 98 Kompleks Pasar Bersehati Manado.

\section{Metode Pengumpulan Data}

Pengumpulan data dilakukan untuk memperoleh informasi yang dibutuhkan dalam rangka mencapai tujuan penelitian (Gulo, 2012 : 110). Dalam proses pengumpulan data yang diperlukan, penulis menggunakan 2 (dua) teknik pengumpulan data yaitu;

1. Interview, yaitu mengadakan wawancara dalam hal ini tanya jawab dengan pimpinan dan staf yang ditujukan untuk mengadakan penelitian terhadap tata cara pelaporan yang menyangkut masalah tersebut.

2. Dokumenter, cara pengumpulan data dengan menggunakan arsip dan dokumen-dokumen dari perusahaan yang bersangkutan.

\section{Metode Analisis}

Analisis yang digunakan penulis dalam menyelesaikan permasalahan dalam penelitian ini adalah dengan menggunakan analisis deskriptif kualitatif. Proses analisis merupakan proses awal dalam tahap perencanaan penyelesaian suatu masalah (Gregory, 2007 : 32). Di dalam penelitian ini, penulis akan mempelajari laporan keuangan yang diperoleh dari perusahaan. kemudian dianalisa apakah proses rekonsiliasi fiskal yang dibuat tersebut sudah benar dan telah sesuai dengan peraturan Perundang - undangan Pajak yang berlaku di Indonesia saat ini.

\section{HASIL PENELITIAN DAN PEMBAHASAN}

\section{Gambaran Umum Objek Penelitian}

\section{Profil perusahaan}

Perseroan didirikan dengan nama PT. Bank Perkreditan Rakyat Swadharma Siau dengan akta notaris Julius Daniel Ismawi. SH. Notaris di Manado tanggal 04 Oktober 1996 nomor 7. Perusahaan mulai beroprasi tanggal 23 mei 1997 di Wilayah Kecamatan Siau Timur dan pada bulan juni 2010 Kantor Pusat yang dulunya di wilayah kecamatan Siau Timur direlokasikan ke Kota madya Manado dengan tetap mempertahankan Kantor di Siau dengan status Kantor Cabang. Sesuai dengan Anggaran Dasar Perusahaan PT. BPR Nusa Utara berusahaan dalam bidang Bank Perkreditan Rakyat

Perusahaan berkedudukan dan berkantor pusat di Jalan Nusantara No. 98 Kompleks Pasar Bersahati Manado. Sesuai dengan Akta Keputusan Rapat dari notaries Paul Tarigan Sh.SpN Nomor 13 tanggal 21 juni 2012 PT. Bank Perkreditan Rakyat Nusa Utara mempunyai Kantor Cabang di Jl. Tatahadeng No 9 Ulu Siau Kab. Kepl Siau Tagulandang Biaro.

\section{Hasil Penelitian}

\section{Laba Rugi Komersial}

Dalam melakukan koreksi fiskal yang akan dikoreksi adalah laporan Laba rugi komersial yang dibuat oleh perusahaan berdasarkan standar akuntansi yang berlaku, untuk dilakukan penyesuaian fiskal berdasarkan peraturan perpajakan yang berlaku. Dimana penelitian akan dilakukan pada Laporan laba rugi komersial yang dibuat oleh PT. BPR Nusa Utara berdasarkan standar akuntansi. Berikut ini yang akan menjadi fokus penelitian untuk analisis koreksi fiskal dalam rangka perhitungan pajak penghasilan badan pada PT. BPR Nusa Utara adalah laporan laba-rugi periode 1 Januari - 31 Desember 2014. Data-data pendukung terkait laporan laba-rugi untuk periode 1 Januari - 31 Desember 2014 juga dapat diperoleh dan dilampirkan, sehingga dapat dilihat rincian penyesuaian fiskal dan dilakukan perhitungan pajak penghasilan badan dari PT. BPR Nusa Utara, untuk mengetahui apakah perusahaan telah melakukan koreksi fiskal sesuai peraturan pajak yang berlaku dalam rangka perhitungan pajak penghasilan badan atau tidak. Laporan laba-rugi 31 Desember 2014 dari PT.BPR Nusa Utara dapat dilihat dalam Tabel 4.2 sebagai berikut. 
Tabel 4.2 Laporan Laba - Rugi PT. Bank Perkreditan Rakyat Nusa Utara Periode 1 Januari - 31 Desember 2014

\begin{tabular}{|c|c|}
\hline \multicolumn{2}{|c|}{$\begin{array}{c}\text { PT. BANK PERKREDITAN RAKYAT NUSA UTARA } \\
\text { LAPORAN LABA-RUGI } \\
\text { Periode 1 Januari - 31 Desember } 2014 \\
\text { (Dinyatakan dalam Rupiah) }\end{array}$} \\
\hline \multicolumn{2}{|l|}{ PENDAPATAN dan BEBAN OPERASIONAL } \\
\hline \multicolumn{2}{|l|}{ PENDAPATAN BUNGA } \\
\hline PENDAPATAN BUNGA KONTRAKTUAL & $3,380,005,000.00$ \\
\hline PENDAPATAN PROVISI/KOMISI & $216,982,000.00$ \\
\hline \multicolumn{2}{|l|}{ BEBAN BUNGA } \\
\hline BEBAN BUNGA KONTRAKTUAL & $(1,138,206,000.00)$ \\
\hline JUMLAH PENDAPATAN BUNGA BERSIH & $2,458,781,000.00$ \\
\hline PENDAPATAN OPERASIONAL LAINNYA & $246,170,000.00$ \\
\hline TOTAL PENDAPATAN OPERASIONAL & 2,704,951,000.00 \\
\hline \multicolumn{2}{|l|}{ BEBAN OPERASIONAL } \\
\hline $\begin{array}{l}\text { BEBAN PENY. PENGHAPUSAN AKT. } \\
\text { PRODUKTIF }\end{array}$ & $157,802,000.00$ \\
\hline BEBAN PEMASARAN & $8,394,000.00$ \\
\hline BEBAN ADMINISTRASI DAN UMUM & $1,711,325,000.00$ \\
\hline BEBAN OPERASIONAL LAINNYA & $19,204,000.00$ \\
\hline TOTAL BEBAN OPERASIONAL & $\mathbf{1 , 8 9 6 , 7 2 5 , 0 0 0 . 0 0}$ \\
\hline LABA (RUGI) OPERASIONAL & $808,226,660.00$ \\
\hline \multicolumn{2}{|l|}{$\begin{array}{l}\text { PENDAPATAN dan BEBAN NON } \\
\text { OPERASIONAL }\end{array}$} \\
\hline PENDAPAPATAN NON OPERASIONAL & $36,793,000.00$ \\
\hline BEBAN NON OPERASIONAL & $84,310,000.00$ \\
\hline $\begin{array}{l}\text { PENDAPATAN (BEBAN) NON } \\
\text { OPERASIONAL }\end{array}$ & $(47,517,000.00)$ \\
\hline $\begin{array}{l}\text { LABA (RUGI) SBELUM PAJAK } \\
\text { PENGHASILAN }\end{array}$ & $760,709,000.00$ \\
\hline
\end{tabular}

Sumber : PT.BPR Nusa Utara

Dari data yang ada, dapat dilihat bahwa PT. Bank perkreditan Rakyat Nusa Utara belum melakukan penyesuaian untuk membayar pembayaran pajak. Dari data yang ada terlihat bahwa PT. Bank Perkreditan Rakyat Nusa Utara mengalami keuntungan sebesar Rp. 760,709,000.00. tetapi data itu hanya berdasarkan laporan keuangan yang ada tanpa dilakukan rekonsiliasi. Hal ini menunjukan bahwa PT. Bank Perkreditan Rakyat Nusa Utara mengikuti Laporan keuangan berdasarkan Standar Akuntansi Keuangan yang ada bukan mengikuti Undang-undang Perpajakan yang berlaku. 


\section{Pembahasan}

Dalam hasil penelitian pada PT. Bank perkreditan Rakyat Nusa Utara, dapat dilihat bahwa perusahaan memiliki suatu laporan laba-rugi yang sesuai dengan Standart Akuntansi Keuangan tapi belum menerapkan prinsip Undang - Undang Perpajakan yang berlaku. Hal ini mungkin saja dapat membuat pihak perusahaan mengalami kekeliruan dalam pembayaran pajak, akan lebih baik jika laporan Laba - Rugi juga di masukan data koreksi fiskal positif dan negatif. Dari data perusahaan berupa laporan keuangan komersial yaitu laporan Laba Rugi, maka dilakukan rekonsiliasi (koreksi) atas laporan laba-rugi komersial menjadi laporan laba-rugi menurut fiskal, untuk menentukan laba kena pajak dalam rangka menghitung Pajak Penghasilan (PPh) badan berdasarkan data-data yang diperoleh terkait dengan hal tersebut.

\section{Rekonsiliasi Fiskal Laporan Keuangan}

Terdapat perbedaan dalam laporan keuangan komersial dan laporan keuangan fiskal. Perbedaan tersebut terjadi karena perbedaan pengakuan pendapatan dan biaya. Oleh karena itu perlu diadakan rekonsiliasi fiskal. Rekonsiliasi laporan keuangan PT. Bank Perkreditan Rakyat Nusa Utara dari komersial ke fiskal adalah sebagai berikut.

Tabel 4.3 Rekonsiliasi Laporan - Laba Rugi Komersial ke Laba - Rugi Fiskal

\begin{tabular}{|c|c|c|c|c|}
\hline \multicolumn{5}{|c|}{ PT. BANK PERKREDITAN RAKYAT NUSA UTARA } \\
\hline \multicolumn{5}{|c|}{ LAPORAN LABA-RUGI KOMERSIAL Ke LABA-RUGI FISKAL } \\
\hline \multicolumn{5}{|c|}{ Periode 1 Januari - 31 Desember 2014} \\
\hline \multicolumn{5}{|c|}{ (Dinyatakan dalam Rupiah) } \\
\hline URAIAN & KOMERSIAL & \multicolumn{2}{|c|}{ KOREKSI FISKAL } & FISKAL \\
\hline $\begin{array}{l}\text { PENDAPATAN dan BEBAN } \\
\text { OPERASIONAL }\end{array}$ & & POSITIVE & NEGATIVE & \\
\hline \multicolumn{5}{|l|}{ PENDAPATAN BUNGA } \\
\hline $\begin{array}{l}\text { PENDAPATAN BUNGA } \\
\text { KONTRAKTUAL }\end{array}$ & $3,380,005,000.00$ & & & $3,380,005,000.00$ \\
\hline PENDAPATAN PROVISI/KOMISI & $216,982,000.00$ & & & $216,982,000.00$ \\
\hline \multicolumn{5}{|l|}{ BEBAN BUNGA } \\
\hline BEBAN BUNGA KONTRAKTUAL & $(1,138,206,000.00)$ & & & $(1,138,206,000.00)$ \\
\hline $\begin{array}{l}\text { JUMLAH PENDAPATAN BUNGA } \\
\text { BERSIH }\end{array}$ & $2,458,781,000.00$ & & - & $2,458,781,000.00$ \\
\hline $\begin{array}{l}\text { PENDAPATAN OPERASIONAL } \\
\text { LAINNYA }\end{array}$ & $246,170,000.00$ & & & $246,170,000.00$ \\
\hline $\begin{array}{r}\text { TOTAL PENDAPATAN } \\
\text { OPERASIONAL }\end{array}$ & $2,704,951,000.00$ & & & $2,704,951,000.00$ \\
\hline \multicolumn{5}{|l|}{ BEBAN OPERASIONAL } \\
\hline \begin{tabular}{l|l} 
BEBAN PENY. PENGHAPUSAN \\
AKT. PRODUKTIF
\end{tabular} & $157,802,000.00$ & & & $157,802,000.00$ \\
\hline BEBAN PEMASARAN & $8,394,000.00$ & & & $8,394,000.00$ \\
\hline $\begin{array}{l}\text { BEBAN ADMINISTRASI DAN } \\
\text { UMUM }\end{array}$ & $1,711,325,000.00$ & $19,286,093.00$ & & $1,692,038,907.00$ \\
\hline BEBAN OPERASIONAL LAINNYA & $19,204,000.00$ & & & $19,204,000.00$ \\
\hline TOTAL BEBAN OPERASIONAL & $1,896,725,000.00$ & & & $1,877,438,907.00$ \\
\hline LABA (RUGI) OPERASIONAL & $808,226,000.00$ & & & $827,512,093.00$ \\
\hline \multicolumn{5}{|l|}{$\begin{array}{l}\text { PENDAPATAN dan BEBAN NON } \\
\text { OPERASIONAL }\end{array}$} \\
\hline \begin{tabular}{l|l} 
PENDAPAPATAN NON \\
OPERASIONAL
\end{tabular} & $36,793,000.00$ & & & $36,793,000.00$ \\
\hline BEBAN NON OPERASIONAL & $84,310,000.00$ & $1,028,500.00$ & & $83,281,500.00$ \\
\hline $\begin{array}{l}\text { PENDAPATAN (BEBAN) NON } \\
\text { OPERASIONAL }\end{array}$ & $(47,517,000.00)$ & & & $(46,488,500.00)$ \\
\hline Total Koreksi Fiskal & & $20,314,593.00$ & & \\
\hline $\begin{array}{l}\text { LABA (RUGI) SBELUM PAJAK } \\
\text { PENGHASILAN }\end{array}$ & $760,709,660.00$ & & & $781,024,253.00$ \\
\hline
\end{tabular}


Berdasarkan data yang dalam tabel 4.3 yang menunjukkan koreksi fiskal dalam rekonsiliasi fiskal atas laporan laba-rugi periode 1 januari - 31 Desember 2014 dari PT. BPR Nusa Utara, dapat dilihat bahwa terdapat 2 akun dalam laporan laba-rugi yang telah dikoreksi positif. Dan tidak ada akun yang dikoreksi negatif. Dalam kedua akun yang dikoreksi fiskal positif tersebut masing-masing terdapat beban-beban yang tidak dapat diakui dalam peraturan perpajakan sebagai beban yang akan mengurangi pendapatan. Maka dari itu, dalam rekonsiliasi fiskal laporan laba-rugi komersial PT.BPR Nusa Utara ke laba-rugi fiskal, akun-akun tersebut harus dikoreksi dan dilakukan penyesuaian fiskal positif yang akan mengakibatkan bertambahnya laba kena pajak dari PT. BPR Nusa Utara.

Akun yang dikoreksi fiskal positif yaitu, akun Beban Administrasi dan Umum dikoreksi positif sebesar Rp.19.286.093,00 dan Akun Beban Non Operasional dikoreksi positif sebesar Rp.1.028.500,00.

Akun Beban Administrasi dan Umum tersebut harus dikoreksi positif, karena berdasarkan catatan Atas laporan Keuangan yang dilampirkan dan informasi yang diperoleh, di dalam akun tersebut terdapat akun beban tenaga kerja yang di dalamnya termasuk beban PPh pasal 21 sebesar Rp.19.286.093,00. Menurut peraturan perpajakan yang berlaku tentang pajak penghasilan yang diatur dalam Pasal 9 ayat (1) huruf a, UU Nomor 36 Tahun 2008 tentang pajak penghasilan, menyatakan bahwa Pajak Penghasilan merupakan biaya yang tidak dapat dikurangkan dari penghasilan bruto. Sehingga beban tersebut harus dikoreksi positif. Jadi dalam rekonsiliasi fiskal akun Beban Administrasi dan Umum dalam Laporan laba/rugi komersial tersebut dikoreksi positif sebesar jumlah beban PPh pasal 21 yang termasuk dalam beban tenaga kerja yaitu Rp.19.286.093,00.

Kemudian akun lainnya yang juga harus dikoreksi positif adalah akun Beban Non Operasional. Karena berdasarkan catatan Atas laporan Keuangan yang dilampirkan, dalam akun Beban Non operasional tersebut termasuk juga beban untuk jamuan tamu sebesar Rp.1.028.500,00. Sesuai dengan peraturan pajak yang berlaku dan menurut Pasal 9 ayat (1) huruf e, UU Nomor 36 Tahun 2008, bahwa beban penggantian atau imbalan sehubungan dengan pekerjaan atau jasa yang diberikan dalam bentuk natura dan kenikmatan, kecuali penyediaan makanan dan minuman bagi seluruh pegawai serta penggantian atau imbalan dalam bentuk natura dan kenikmatan di daerah tertentu yang berkaitan dengan pelaksanaan pekerjaan yang diatur dengan atau berdasarkan Peraturan Menteri Keuangan, maka untuk jamuan tamu tidak dapat diakui sebagai beban yang akan mengurangi penghasilan bruto. Sehingga beban jamuan tamu tersebut harus dikoreksi positif. Jadi, dalam rekonsiliasi fiskal akun Beban Non Operasioanl dalam laporan labarugi komersial tersebut harus dikoreksi positif sesuai dengan jumlah beban jamuan tamu yang terdapat di dalamnya yaitu Rp. 1.028.500,00.

Berikut adalah penyesuaian Fiskal yang dilakukan oleh PT.BPR Nusa Utara berdasarkan data dalam Catatan Atas laporan Keuangan periode 1 Januari - 31 Desember 2014, yang telah dilampirkan.

\section{Laba Bersih Sebelum Pajak Penghasilan Menurut Akuntansi}

$=$ Rp. 760.709.660,00 Koreksi Fiskal:

- Fiskal Positif:

- Jamuan Tamu

- PPh Pasal 21

$$
\begin{aligned}
& =\text { Rp. } 1.028 .500,00 \\
& =\text { Rp. } 19.286 .093,00
\end{aligned}
$$

- Fiskal Negatif:

- Pengahsilan yang dikenakan PPh Final

\section{Jumlah Koreksi Fiskal} (Bunga tabungan/Dep/Jasa Giro)

\section{Laba Sebelum Pajak Penghasilan Menurut Fiskal (Laba Fiskal)}

$=$ Rp. 781,024,253.00

Jadi, berdasarkan data koreksi fiskal yang diperoleh, diketahui bahwa laba sebelum pajak menurut akuntansi dari PT.BPR Nusa Utara adalah sebesar Rp.760.709.660,00. Kemudian dilakukan koreksi fiskal positif sebesar Rp.20.314.593,00 yang terdiri dari beban jamuan tamu sebesar Rp.1.028.500,00 dan beban PPh pasal 21 sebesar Rp.19.286.093,00.

Koreksi positif tersebut akan mengakibatkan bertambahnya laba sebelum pajak menurut akuntansi dari PT.BPR Nusa Utara yang berjumlah Rp.760.709.660,00 bertambah sejumlah koreksi fiskal positif yaitu Rp.20.314.593,00 menjadi Laba sebelum pajak menurut fiskal (Laba Fiskal) sejumlah Rp.781,024,253.00 


\section{Perhitungan PPh Badan}

Berikut disajikan perhitungan Pajak Penghasilan Badan dari PT.BPR Nusa Utara yang telah dilakukan oleh perusahaan berdasarkan data yang tercantum dalam Catatan Atas laporan Keuangan PT.BPR Nusa Utara yang terlampir.

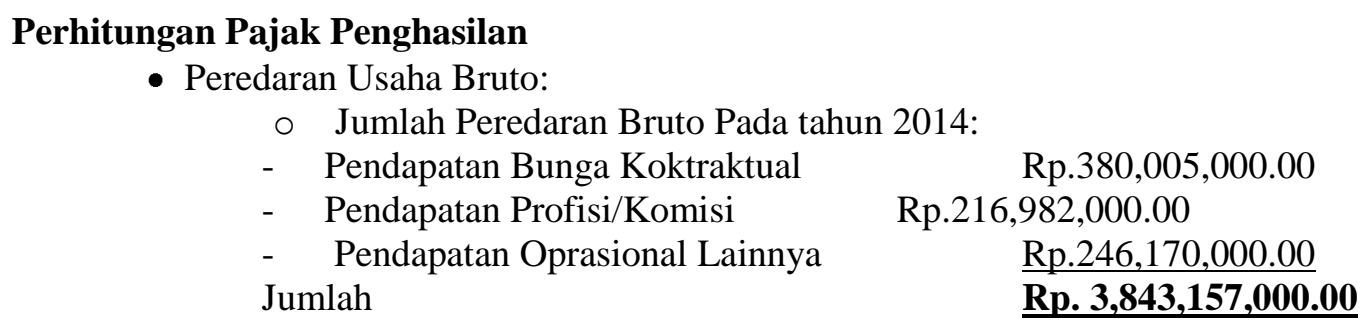

Dengan demikian perhitungan $\mathrm{PPh}$ terutang adalah berdasarkan pasal 31 E Undang-undang No. 36 Tahun 2008 Tentang Pajak Penghasilan, yang peredaran brutonya di bawah 4,8 milyard s/d 50 milyard. Menyatakan bahwa, untuk badan mengenai fasilitas penurunan tarif pajak sebesar 50\% dari PKP yaitu, apabila peredaran usaha sampai dengan 50 milyard per tahun, memperoleh fasilitas penurunan tarif pajak sebesar 50\% atas PKP dari bagian peredaran usaha sebesar 4,8 milyard.

PT.BPR Nusa Utara diketahui memiliki peredaran bruto yang tidak melebihi 50 milyard per tahun, sehingga PT.BPR Nusa Utara menerima fasilitas penurunan tarif pajak sebesar 50\% dari PKP. Perhitungannya sebagai berikut.

- Tarif Pajak:

$50 \%$ x $25 \%$ x Rp.781,024,000.00

$=$ Rp. $97,628,000.00$

- $\mathrm{PPh}$ Pasal 25 yang telah disetor tahun $2014=\mathrm{Rp} .25,549,203.00$

- Utang Pajak (PPh Pasal 29) per 31 Desember 2014 = Rp.72,078,797.00

Perhitungan tarif pajak di atas merupakan perhitungan tarif pajak tahunan. Pada laporan laba-rugi PT.BPR Nusa Utara perlu dikurangi beban pajak karena laporan tersebut adalah laporan laba-rugi periode 1 Januari - 31 Desember 2014 yang merupakan periode pembayaran pajak.

Untuk ketentuan pelaporan dan pembayaran pajak, jumlah pajak yang harus dibayar sebelum koreksi fiskal akan berbeda dengan jumlah pajak yang harus dibayar setelah dilakukan koreksi fiskal. Laba bersih dalam laporan laba rugi komersial adalah sebesar Rp.760.709.660,00. Sedangkan laba bersih setelah dikoreksi fiskal adalah Rp.781.024.235,00. Kemudian diketahui perusahaan memiliki peredaran Bruto pada tahun 2014 adalah sebesar Rp.3.843.258.773,00. Maka, hasil perhitungan tarif pajak dan PPh terutang dari PT.BPR Nusa Utara yang sesuai dengan peredaran brutonya dan berdasarka peraturan yang berlaku menghasilkan utang pajak $(\mathrm{PPh}$ pasal 29) periode 1 Januari - 31 Desember 2014 sebesar Rp.72.078.797,00.

\section{PENUTUP}

\section{Kesimpulan}

Berdasarkan hasil penelitian dan pembahasan yang telah dilakukan pada PT. BPR Nusa Utara, maka dapat ditarik kesimpulan sebagai berikut.

1. Koreksi fiskal sangat perlu dilakukan karena dapat membantu dalam rangka perhitungan pajak penghasilan badan dari PT.BPR Nusa utara, sehingga pihak PT.BPR Nusa Utara dapat melakukan pembayaran pajak secara benar sesuai dengan peraturan perpajakan yang berlaku.

2. Terdapat 2 akun yang dikoreksi fiskal positif dalam laporan laba-rugi komersial PT.BPR Nusa Utara. Pertama, yaitu Biaya Jamuan tamu sebesar Rp.1,028,500.00 yang termasuk dalam beban non operasional. Dan kedua adalah PPh Pasal 21 sebesar Rp. 19,286,093.00. Koreksi Poritif tersebut mengakibatkan bertambahnya laba kena pajak PT.BPR Nusa Utara 31 Desember 2014 sejumlah Rp.20,314,593.00.

3. PT. Bank Perkreditan Rakyat Nusa Utara telah membuat koreksi fiskal dalam rangka perhitungan Pajak Penghasilan Badan dari laporan Laba/Rugi fiskal untuk 31 Desember 2014 dengan benar dan sesuai dengan peraturan undang-undang perpajakan yang barlaku. Laba bersih sebelum pajak berdasarkan perhitungan dalam laporan laba-rugi komersial 31 Desember yang diperoleh PT.BPR Nusa Utara 
adalah sebesar Rp.760,709,660.00. Kemudian setelah dilakukan koreksi fiskal atas laporan laba rugi komersia, maka diketahui bahwa laba bersih sebelum pajak menurut fiskal yang dimiliki PT.BPR Nusa Utara adalah sebesar Rp. 781,024,235.00.

4. Perhitungan pajak penghasilan badan PT.BPR Nusa Utara telah dilakukan sesuai tarif pajak yang berlaku berdasarkan peredaran bruto perusahaan dan dengan menggunakan laba bersih sebelum pajak menurut fiskal.

\section{Saran}

Berdasarkan pembahasan dan kesimpulan yang telah diuraikan terdapat beberapa saran yang dapat diberikan untuk PT BPR Nusa Utara yaitu, sebagai berikut.

1. PT. BPR. Nusa Utara sebaiknya selalu menyertakan penyesuaian fiskal dalam membuat Laporan LabaRugi perusahaan. Sehingga perusahaan dapat selalu melakukan pembayaran pajak penghasilan yang benar berdasarkan dengan laba kena pajak menurut fiskal dan sesuai dengan peraturan perpajakan yang berlaku.

2. Perusahaan harus lebih memperhatikan aspek-aspek yang harus dikoreksi fiskal sesuai dengan peraturan perpajakan yang berlaku atas pengakuan pendapatan-pendapatan dan beban-beban, agar supaya dapat dilakukan penyesuaian fiskal yang tepat dan tidak terdapat kekeliruan dalam pembayaran pajak.

\section{DAFTAR PUSTAKA}

Abdi Siregar (2011). “AnalisisKoreksi Fiskal Untuk Menghitung Besarnya PPh Terhutan Pada PT. Perkebunan Nusantara III (Persero) Medan”. Skripsi

Ayu Dwijayanti (2013). "Analisis Koreksi Fiskal atas Laporan Keuangan Komersial pada PT. Citra Sulawesi Sejahtera di Makassar". Skripsi. Universitas hassanudin Makasar

Badan Pusat 2011. Statistik. Penerimaan Negara Indonesia. http://www.pbs.go.id/tab_sub/view.php?tabel=1\&id_subyek=13

Dewi Yuniarti (2008), "Rekonsiliasi Fiskal atas Laporan Keuangan Komersial Untuk Menentukan Pajak Penghasilan (Studi Pada Laporan Keuangan 2007 PT.BPR Nusamba Ngunut Tulungagung)”. Skripsi

Felix Wongso (2013). “Analisis Koreksi Fiskal Dalam Rangka Perhitunga PPh Badan pada PT. Kawanua Dasa Pratama". Skripsi. Universitas Sam Ratulangi Manado

Gustian Djuanda dan Irwansyah Lubis (2006). Pelaporan Pajak Penghasilan, Edisi Revisi. Gramedia Pustaka Utama. Jakarta

Hastoni, Robert Pardede, Yuni Astuti (2009). "Pengaruh Rekonsiliasi Fiskal terhadap perhitungan PPh Terutang pada PDAM Tirta Pakuan Bogor”. Jurnal Ilmiah Rangga Gading. Vol. 9 No. 1:34-37

Horgngren dan Harrison (2007). Akuntansi, Jilid Satu. Edisi Tujuh. Penerbit Erlangga. Jakarta

Januarsi, Yeni (2013). Laporan Keuangan Menurut http://newsakuntansi.blogspot.com/2013/05/pengertian-laporan-keuangan-menurut.html

"Koreksi positif dan Negatif" Kategori Forum : $\mathrm{PPh}$ Badan. http://ortax.org/ortax/?mod=forum\&page=show\&idtopik

Livers Mary.L (2012). "Balancing Fiscal challenges performance-based Budgeting and Public Safety". NIC advisory Board Public Hearing.

Moh. Nazir. Ph.D (2005), Metode Penelitian, Ghalia Indonesia. Bogor

Mardiasmo (2008). Perpajakan . Penerbit Andi. Yogyakarta

Mills, F. Lilian. George, A.Plesko (2003). "Bridging the reporting gap : a proposal for more informative reconciling of book and tax income." Papers. University Of Arizona. http://www.brookings.edu

Muljono, Djoko (2007). Pengantar PPh dan PPh 21 lengkap dengan Undang-undang. Penerbit Andi. Yogyakarta

Muljono, Djoko (2007). Akuntansi Pajak Edisi Revisi. Penerbit Andi. Yogyakarta 
Najiyullah (2010). Analisis Perhitungan, Pemotongan, Penyetoran, dan Pelaporan wajib Pajak Penghasilan Pasal 21 Pada PT. Hikerta Pratama. Skripsi

Paulo medas, Daria Zakharova (2009). A Primer on Fiscal Analysis in Oil Production Countries. Fiscal Affairs Departement. International Monitary Fund Paper. WP/09/56

Pambudi, Kutut (2010). http://hukum-pajak.blogspot.com/2010/04/tata-cara-pemungutan-pajak.html

Prang Buwono (2012). "Analisis Koreksi Fiskal atas Laporan Keuangan Komersial Pada CV.Reviana”. Skripsi. Universitas Gunadarma Jakarta. www.gunadarma.ac.id

Rampengan R.R (2013). "Analisis Perhitungan dan Pelaporan Pajak Penghasilan Pasal 23 pada PT.Hasjrat Multifinance Manado". Jurnal Riset Akuntansi Going Concern. Vol.9 No.1

Resmi, Siti (2011). Perpajakan Teori dan Kasus. Penerbit Salemba Empat. Jakarta

Setiawati, Lilis (2009). Pedoman dan Cara Pengisian SPT PPh pasal 21. Penerbit Andi. Yogyakarta.

Sekar Ayu Rosita (2011). "Penerapan Rekonsiliasi Fiskal dan Perhitungan nilai Beda Temporer untuk Menyusun Laporan Keuangan berdasarkan PSAK. 46 pada PT.Bumi Lingga Pertiwi Gersik". Skripsi. STIE PERBANAS Surabaya

Sofyan Syafri Harahap (2006). Analisis Kritis Atas Laporan Keuangan. Edisi Satu. PT Raja Grafindo Persada. Jakarta

Sugiyono (2010). Metode Penelitian Kuantitatif, Kualitatif. Penerbit ALFABETA

Suwardjono (2005). Teori Akuntansi. Edisi Ketiga. BPFE. Yogyakarta

Togar, Ridho (2013). http://ridhotogar.blogspot.com/2013/03/konsep-konsep-dasar-akuntansi.html

Undang-undang Nomor 36 Tahun 2008, Tentang Pajak Penghasilan

Waluyo (2011). Perpajakan Edisi 10 - buku 1. Salemba Empat. Jakarta

Walandow (2013). “Analisis Perhitungan dan Pelaporan PPh Pasal 23 dan PPh Pasal 25”. Skripsi. Universitas Sam Ratulangi Manado

Waluyo (2012). Perpajakan Indonesia I. Salemb Empat. Jakarta

Warren et all., (2005). Pengantar Akuntansi, Edisi 21. Salemba Empat. Jakarta

Wibowo (2012). Pajak. http://wibowo-pajak.blogspot.com/2012/01/pengertian-koreksi-fiskal.html

Wicaksono, Baruni (2009). Akuntansi Pajak Lnjutan. Penerbit Andi. Yogyakarta

Y.D wongkar (2015). "Analisis Laporan Keuangan untuk Menilai Kinerja Laporan Keuangan PT.BPR Nusa Utara". Jurnal EMBA ISSN 2303-1174. Vol. 3 No. 2: 365-373

Zidna, zaidan (2008). Pajak Indonesia. http://pajakindonesia.wordpress.com/2008/02/28/koreksi-fiskal/ 